\title{
First report of tomato spotted wilt virus in Lycium chinense
}

\author{
Hae-Ryun Kwak ${ }^{1}$ (D) S Seung-Wan Son ${ }^{2} \cdot$ Hyeon-Yong Choi ${ }^{1}$ - Woo-Ri Go ${ }^{1}$ • Jeong-Eun Kim ${ }^{1}$ - Eseul Baek ${ }^{1}$. \\ Mikyeong Kim ${ }^{1} \cdot$ Hong-Soo Choi ${ }^{1}$
}

Received: 6 August 2019 / Accepted: 15 January 2020 / Published online: 23 January 2020

(C) Australasian Plant Pathology Society Inc. 2020

\begin{abstract}
Tospovirus transmitted by thrips can cause serious diseases in many economically important plants. Based on molecular and biological assays, a virus infecting boxthorn plants in Korea was identified as tomato spotted wilt virus (TSWV). To the best of our knowledge, this is the first report of TSWV in L. chinense.
\end{abstract}

Keywords Boxthorn · Tospovirus · Thrips

Boxthorn (Lycium chinense) is a deciduous shrub belonging to the Solanaceae family and is a well-known medicinal plant in Asia (Kim and Chung 2009; Qian et al. 2004). In Korea, production and consumption of this plant have gradually increased due to its medicinal and nutritional value. In May 2018, virus-like symptoms, such as chlorotic and necrotic spots and mosaic on the leaves, necrosis on the stems, and stunting were observed on boxthorn plants in open fields and greenhouses in the Cheongyang area of South Korea (Fig. 1). Disease incidence was greater than $60 \%$ in approximately $1000 \mathrm{~m}^{2}$ of cultivated land. Tomato spotted wilt virus (TSWV) has recently been found to be problematic in chili plants in this important chili cultivation region of South Korea (Kwon et al., 2018).

TSWV, as a member of the genus Orthotospovirus of family Tospoviridae, is transmitted by thrips and causes a serious disease in many economically important plants, including pepper

Hae-Ryun Kwak, Seung-Wan Son and Hong-Soo Choi contributed equally to this work.

Electronic supplementary material The online version of this article (https://doi.org/10.1007/s13314-020-0374-1) contains supplementary material, which is available to authorized users.

Hae-Ryun Kwak

hrkwakhahn@korea.kr

Hong-Soo Choi

hschoi@korea.kr

1 Crop Protection Division, National Institute of Agricultural Sciences, Rural Development Administration, Wanju 55365, Republic of Korea

2 Boxthorn Experiment Station of Chungnam-Do ARES, Cheongyang 33319, Republic of Korea and tomato (Parrella et al. 2003). TSWV has been reported to infect other Lycium spp., such as Lycium ferocissimum and Lycium procissimum (Edwardson and Christie, 1997).

We collected ten symptomatic boxthorn plant samples from two greenhouses and open fields, and then performed reverse transcription (RT)-PCR for TSWV, broad bean wilt virus 2, and cucumber mosaic virus, belonging to major pepperinfecting viruses in Korea. As a result, they were found to be infected with TSWV using specific primer pairs (TSWV-5F: 5'-GCACAACACACAGAAAGCAAA-3', TSWV-6R: 5'AGAGCAATCGTGTCAATTTTATTC-3') designed to amplify $1065 \mathrm{bp}$ including the $\mathrm{N}$ gene based on reported nucleotide sequences of S segments of TSWV isolates in GenBank (Supplementary Table S1). Amplified fragments were obtained from all the leaf samples and directly sequenced. The nucleotide sequences among the ten isolates showed 98 to $100 \%$ identity to several pepper-infecting isolates from South Korea, including TSWV-YY (Genbank accession MF159073) and TSWV-CY (MF159063).

In order to isolate TSWV from boxthorn, sap from symptomatic leaves was inoculated mechanically to Nicotiana tabacum cv. 'Samsun' via three single-lesion passages. This procedure was followed by propagation in N. rustica, and the isolate was named TSWV_CY-LC. To investigate the host range of TSWV_CY-LC, sap from infected N. rustica was inoculated on 34 indicator plants, including boxthorn (Table 1). TSWV_CY-LC induced the following symptoms in 19 indicator plants (Fig. 2 \& supplementary fig. S4): chlorotic ring spots, necrotic local lesions, and mosaic in $N$. rustica (Fig. 2a); necrotic local lesions and mosaic in N. clevelandii, $N$. glutinosa, and N. occidentalis; mosaic and distortion in Capsicum annuum (Fig. 2b); mosaic in N. benthamiana and Solanum lycopersicum; necrotic local lesions in 
Fig. 1 Symptoms of TSWV on leaves of boxthorn. (a) Necrotic ring spots and (b) chlorosis on the leaves of naturally infected boxthorn plants
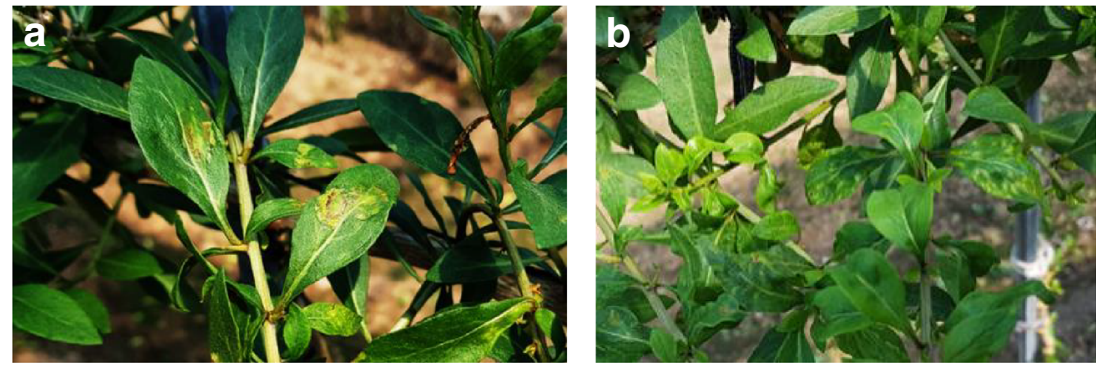

Chenopodium quinoa, $N$. debneyi, $N$. tabacum cv. 'Xanthinc', and Physalis angulata L.; necrotic local lesions in inoculated leaves of Petunia hybrida, Vicia faba, Cucurbita moschata, and Gomphrena globosa; and pinpoint local lesions in inoculated leaves of Chenopodium amaranticolor.

Table 1 Symptoms observed on indicator plants mechanically inoculated with TSWV_CY-LC isolate from boxthorn

\begin{tabular}{|c|c|c|c|}
\hline Indicator plant & & Symptoms $^{\mathrm{a}}$ & $\begin{array}{l}\text { TSWV } \\
\text { incidence }^{b}\end{array}$ \\
\hline \multirow[t]{12}{*}{ Solanaceae } & Lycium chinense Mill & $\mathrm{cs}, \mathrm{ns} / \mathrm{cl}, \mathrm{m}$ & $3 / 3$ \\
\hline & Nicotiana rustica & $\mathrm{nl}, \mathrm{m}, \mathrm{rs} / \mathrm{nl}, \mathrm{m}, \mathrm{rs}$ & $3 / 3$ \\
\hline & Nicotiana clevelandii & $\mathrm{nl} / \mathrm{nl}, \mathrm{m}$ & $3 / 3$ \\
\hline & Nicotiana glutinosa & $\mathrm{nl} / \mathrm{nl}, \mathrm{m}$ & $3 / 3$ \\
\hline & Nicotiana occidentalis & $\mathrm{nl} / \mathrm{nl}, \mathrm{m}$ & $3 / 3$ \\
\hline & Nicotiana debneyi & $\mathrm{nl} / \mathrm{nl}$ & $3 / 3$ \\
\hline & $\begin{array}{l}\text { Nicotiana tabacum cv. } \\
\text { 'Xanthi-nc' }\end{array}$ & $\mathrm{nl} / \mathrm{nl}$ & $3 / 3$ \\
\hline & Nicotiana benthamiana & $\mathrm{nl} / \mathrm{m}$ & $3 / 3$ \\
\hline & Solanum lycopersicum & $-/ \mathrm{m}$ & $2 / 3$ \\
\hline & Capsicum аппиит & $\mathrm{nl} / \mathrm{m}$, distortion & $3 / 3$ \\
\hline & Physalis angulata $L$. & $\mathrm{nl} / \mathrm{nl}$ & $3 / 3$ \\
\hline & Petunia hybrida & ns/- & $3 / 3$ \\
\hline \multirow[t]{6}{*}{ Leguminosae } & Vicia faba & $\mathrm{nl} /-$ & $3 / 3$ \\
\hline & Pisum sativum & $\mathrm{nl} / \mathrm{nl}$ & $3 / 3$ \\
\hline & Phaseolus vulgaris & $-1-$ & $0 / 3$ \\
\hline & Vigna unguiculata & $-1-$ & $0 / 3$ \\
\hline & Vigna radiata & $-1-$ & $0 / 3$ \\
\hline & Vigna angularis & $-1-$ & $0 / 3$ \\
\hline \multirow[t]{2}{*}{ Chenopodiaceae } & $\begin{array}{l}\text { Chenopodium } \\
\text { amaranticolor }\end{array}$ & $\mathrm{pp}, \mathrm{nl} /-$ & $3 / 3$ \\
\hline & Chenopodium quinoa & $\mathrm{nl} / \mathrm{nl}$ & $3 / 3$ \\
\hline \multirow[t]{4}{*}{ Cucurbitaceae } & Cucurbita moschata & $\mathrm{nl} /-$ & $2 / 3$ \\
\hline & Cucumis melo & $-1-$ & $0 / 3$ \\
\hline & Cucumis sativus & $-1-$ & $0 / 3$ \\
\hline & Citrullus lanatus & $-1-$ & $0 / 3$ \\
\hline Amaranthaceae & Gomphrena globosa & $\mathrm{nl} /-$ & $3 / 3$ \\
\hline \multirow[t]{3}{*}{ Brassicaceae } & Brassica campestris & $-1-$ & $0 / 3$ \\
\hline & Brassica juncea & $-1-$ & $0 / 3$ \\
\hline & Raphanus sativus & $-1-$ & $0 / 3$ \\
\hline \multirow[t]{5}{*}{ Malvaceae } & Malva verticillata & $-1-$ & $0 / 2$ \\
\hline & Alcea rosea & $-1-$ & $0 / 2$ \\
\hline & Abelmoschus esculentus & $-1-$ & $0 / 2$ \\
\hline & Hibiscus rosa-sinensis & $-1-$ & $0 / 2$ \\
\hline & Hibiscus mutabilis & $-1-$ & $0 / 2$ \\
\hline Aizoaceae & Tetragonia tetragonioides & $-1-$ & $0 / 3$ \\
\hline
\end{tabular}

${ }^{a}$ cl, chlorotic local lesions; cs, chlorotic spots; nl, necrotic local lesions; ns, necrotic spots; m, mosaic;

rs, ring spots; pp., pinpoint; -, no symptom; ${ }^{b}$ No. of plant infected / No. of plant inoculated
On inoculated boxthorn plants, chlorotic and necrotic spots (Fig. 2c) and mosaic symptoms (Fig. 2d) were reproduced, which were similar to those in the original isolate. No symptoms were observed in an additional 15 indicator plants tested.

To genetically characterize TSWV_CY-LC, the complete genome sequence of TSWV_CY-LC was obtained using RTPCR using the specific primers described in the supplementary Table S1 (Lee et al., 2011). Total RNA was extracted from the infected leaf samples using an Easy-spin Total RNA Extraction Kit (Intron Biotech., Seongnam, Korea), following the manufacturer's instructions. Two-step RT-PCR was carried out using AMV reverse transcriptase (Promega, Madison, WI, USA) and high-fidelity LA Taq polymerase (Takara, Tokyo, Japan) for full-length genome sequencing. Tripartite full-length genomes of TSWV were amplified using virus-specific primer pairs. The sizes of each amplified fragment ranged from 0.8 to $1.2 \mathrm{~kb}$, and each fragment overlapped with its neighboring fragments by at least 100 nucleotides. Terminal sequences were obtained following the protocol for 5'- and 3'- rapid amplification of cDNA ends (RACE; Boehringer Mannheim, Germany). cDNA clones containing the $5^{\prime}$-end of the genomes were obtained using Xec primer (5'-
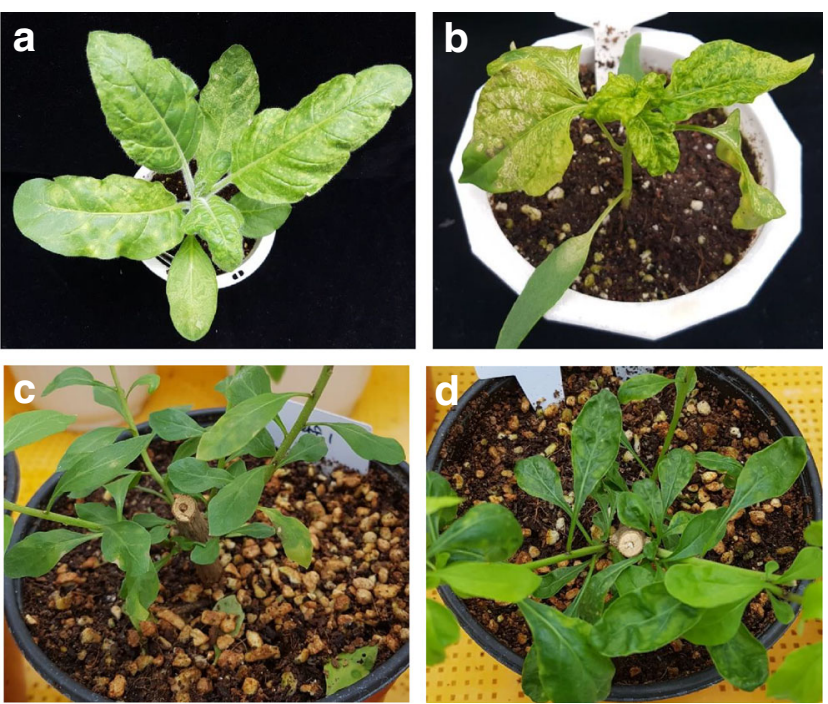

Fig. 2 Symptoms on indicator plants inoculated mechanically with TSWV isolate CY-LC. (a) Nicotiana rustica, (b) Capsicum annuum, (c) Lycium chinense Mill (Hasoo cultivar), and (d) Lycium chinense Mill (Cheonghong cultivar) 
AAAGAATTCCCCCCCCCCCCC-3') and TSWV 5'-race-R primer complementary to the nucleotides of TSWV-L, $-\mathrm{M}$, and-S RNAs. In addition, cDNA clones containing the 3 '-end of the genomes were obtained using TSWV 3'-race-F primer complementary to the nucleotides of TSWV-L, -M, and -S RNAs and an anchor primer (5'-GACCACGCGTATCG ATGTCGACTTTTTTTTTTTTTTTTV-3'). Each PCR fragment was purified using a MEGA Quick-spin ${ }^{\mathrm{TM}} \mathrm{Kit}$ (Intron, Korea) and cloned into the pGEM-T easy vector (Promega, Madison, WI, USA), according to the manufacturer's instructions, and transformed into Escherichia coli DH5 $\alpha$. Sequencing of purified recombinant cloned DNAs was performed by a commercial company (Bionics, Daejeon, Korea). The sequences obtained were assembled using DNA Star v. 5.02 (Lasergene, USA) and the assembled full-length sequences of L, M, and S segments were 8914, 4772, and 2972 nucleotides in length, respectively, and these were deposited in GenBank under the accessions MN064722, MN064723, and MN064724, respectively. The full-length sequences of each segment were aligned with those of previously reported isolates (Supplementary Table S2) using 'Geneious alignment' program in Geneious Pro 10 software. The phylogenetic trees based on full-length sequences of each segment were analyzed by the maximum likelihood (ML) method in MEGA 7 (Kumar et al. 2016). Phylogenetic analysis revealed that the sequences of each segment were clustered, respectively, with TSWV-L, $-\mathrm{M}$, and $-\mathrm{S}$ RNAs of TSWV-YY (MF159049, MF159061, and MF159073) and TSWV-CY (MF1590393, MF159051, and MF159063) isolated from peppers in Korea with the highest nucleotide identities of $99 \%$.

TSWV has been problematic in various crops in Korea since its first detection in 2003 (Kim et al. 2004). As boxthorn may serve as an intermediate host of TSWV for other crops, such as pepper, the identification of TSWV infection in boxthorn can help prevent and control the disease in boxthorn and other crops susceptible to TSWV in Korea.

Acknowledgments This research was supported by grants from the Agenda Program (PJ01130602) funded by the Rural Development Administration of Korea.

\section{References}

Edwardson JR and Christie RG. (1997). Viruses infecting peppers and other solanaceous crops. Vol. 2, pp 687-719, University of Florida. Agricultural Experiences Station, Gainesville, FL, USA

Kim JH, Choi GS, Kim JS, Choi JK (2004) Characterization of tomato spotted wilt virus from paprika in Korea. Plant Pathol J 20:297-301

Kim JS, Chung HY (2009) GC-MS analysis of the volatile components in dried boxthorn (Lycium chinensis) fruit. J Korean Soc Appl Biol Chem 52:516-524

Kumar S, Stecher G, Tamura K (2016) MEGA7: molecular evolutionary genetics analysis version 7.0 for bigger datasets. Mol Biol Evol 33: $1870-1874$

Kwon SJ, Cho IS, Yoon JY, Chung BN (2018) Incidence and occurrence pattern of viruses on peppers growing in fields in Korea. ResPlant Dis 24:66-74

Lee JS, Cho WK, Kim MK, Kwak HR, Choi HS, Kim KH (2011) Complete genome sequences of three tomato spotted wilt virus isolates from tomato and pepper plants in Korea and their phylogenetic relationship to other TSWV isolates. Arch Virol 156:725-728

Parrella G, Gognalons P, Gebre-Selassie K, Vovlas C, Marchoux G (2003) An update of the host range of tomato spotted wilt virus. J Plant Pathol 85:227-264

Qian JY, Liu D, Huang AG (2004) The efficiency of flavonoids in polar extracts of Lycium chinense mill fruits as free radical scavenger. Food Chem 87:283-288 